\title{
Homeownership and Local Voting in Disadvantaged Urban Neighborhoods
}

\author{
Kim Manturuk \\ Mark Lindblad \\ Roberto G. Quercia \\ The University of North Carolina at Chapel Hill
}

\begin{abstract}
Homeownership has long been considered the cornerstone of the American dream, and considerable research has pointed to the social benefits of homeownership for both families and communities. Yet research concerning this link between homeownership and social participation has recently undergone critique for failing to consider neighborhood context. Do homeowners in disadvantaged urban neighborhoods become active participants in neighborhood improvement, or do they feel stuck in undesirable neighborhoods where they perceive little potential for change? The research addresses endogeneity concerns and shows that, when compared with renters, homeowners are more likely to have voted in recent local elections. Neighborhood context does moderate this relationship, with homeowners in disadvantaged neighborhoods being more likely to vote than owners in other areas. These findings suggest that, despite potential household-level costs associated with owning a home in a disadvantaged urban area, responsible homeownership in such areas promotes local political involvement among lower income residents.
\end{abstract}

\section{Introduction}

Recent research has linked homeownership with a variety of beneficial social outcomes, including increased community involvement, more diverse social capital resources, and greater civic engagement (Dietz and Haurin, 2003; Rossi, 1996). Two significant critiques of such studies have emerged, however: one theoretical and one analytical. Because the empirical association between homeownership and positive social outcomes has been undertheorized, few studies have considered whether the benefits of homeownership extend equally to all owners or whether they 
are moderated by neighborhood characteristics. It is possible that the strain associated with living in disadvantaged urban neighborhoods could be compounded for homeowners in those areas, who are generally less mobile than renters (Rohe, Van Zandt, and McCarthy, 2000). Homeowners in poor neighborhoods, particularly lower income owners, risk losing their largest source of wealth if their home value declines because they have fewer options to transfer their wealth to a less risky investment by moving to a better neighborhood. Low-income residents are also more dependent on social ties and informal exchange and support networks within their local communities (Stack, 1997), so moving to a different neighborhood extracts both economic and social costs for homeowners, which can take time to recoup. In this study, we evaluate whether homeowners in lower income neighborhoods are more likely to participate in local elections to address these challenges and whether "neighborhood effects" moderate the relationship between homeownership and local voting.

A second, analytical critique of studies on homeownership and social outcomes is that many researchers have failed to account for the self-selectivity of homeowners, leading to bias in analyses comparing social outcomes of homeowners and renters (Aaronson, 2000; Dietz and Haurin, 2003; Rohe, Van Zandt, and McCarthy, 2000). People self-select into homeownership, and the predictors of homeownership are often similar to the predictors associated with local political participation and civic involvement (DiPasquale and Glaeser, 1999). Because this endogeneity exists within the models, attempts to model the effect of homeownership on outcomes such as voting may produce biased results. In past research, it has often been impossible to determine whether homeownership is associated with increased political participation, independent of the predictors common to both outcomes.

In this study, we address both theoretical and analytical concerns by exploring whether homeowners are more likely than renters to vote in local elections and, if so, whether this outcome is realized equally for homeowners in all neighborhoods or whether the association found in previous studies is context dependent. We use a modification of statistical techniques proposed by Dietz and Haurin (2003), discussed in detail later in this article, to account for endogeneity, thus ensuring that our analysis treats the actual effects of homeownership.

\section{Contributions}

This study offers three key contributions. First, it addresses unanswered questions about the role of homeownership in promoting local voting among lower income citizens. Urban low-income residents have historically been seen as less politically active or engaged in civic life than other groups due to the relative lack of opportunities for activism in disadvantaged areas (Wilson, 1990). This relative lack of political engagement means that some of the most disadvantaged citizens may be cut off from the local political structures that could afford them increased opportunities. Recent research has indicated, however, that economic disadvantage can spur political activity when people have a sense of collective efficacy and positive past experiences with government (Lawless and Fox, 2001). This study tests whether homeownership increases political engagement—specifically local voting - among lower income citizens. If indeed homeownership does increase voting, our research will provide support for the claim that homeownership can potentially foster democratic participation in disadvantaged urban neighborhoods. 
Second, our findings speak to an ongoing debate about the value of encouraging homeownership in disadvantaged areas. Although policymakers have focused on promoting homeownership among lower income families as a means of wealth building, some scholars have recently questioned this position (Shlay, 2006). Rohe, Van Zandt, and McCarthy (2000) argued that neighborhood revitalization efforts aimed at increasing homeownership in disadvantaged neighborhoods can result in homeowners' feeling trapped in depreciating neighborhoods that offer them few opportunities for civic or community involvement. These scholars argued that, although there are clear social benefits to homeownership, insufficient research has been done on the social costs associated with ownership. They wrote, "Future research needs to better identify the circumstances under which ownership leads to both positive and negative outcomes" (Rohe, Van Zandt, and McCarthy 2000: 402). Our research offers empirical evidence as to whether neighborhood disadvantage affects the degree to which homeowners participate in local political activities.

Finally, this analysis uses a method that takes into account the fact that homeownership and political participation share an overlapping set of predictors. We use a bivariate probit model that allows homeownership and political participation to vary jointly with an overlapping set of covariates. We first model homeownership and then use predicted probabilities of homeownership in a second-stage model predicting local voting. This model provides an explicit test of the relationship between homeownership and voting and improves on previous models that have failed to account for endogeneity in this relationship.

\section{Background}

A key benefit of a democratic society is the ability of its citizens to participate in their own government. Both social and financial factors explain why lower income homeowners may be more likely to vote than similar renters. First, homeowners have a financial motive to maintain desirable neighborhood and property conditions, because the values of their homes are partially tied to the larger community (Rohe and Stewart, 1996). For this reason, local political participation yields not only quality-of-life benefits but also long-term economic benefits for homeowners. Renters experience the same quality-of-life benefits of political participation but not the economic ones. In fact, one study suggests that as neighborhoods improve as a result of active local political and civic groups, market-rate rents are likely to increase because the neighborhoods become more desirable (DiPasquale and Glaeser, 1999). Improved local amenities and better neighborhood conditions translate to a gain for homeowners as their home values increase but a financial loss for renters as their rents increase.

Second, renters have more flexibility than homeowners to relocate if community conditions become unfavorable. Orbell and Uno (1972) described how people make choices about responding to unfavorable neighborhood conditions. They argued that people have three options: leave the neighborhood, attempt to change the neighborhood, or do nothing. Setting aside the "do nothing" option, the options amount to an "exit or voice" decision (Hirschman, 1970); how do people decide whether to move away or work for change? We argue that homeownership (versus renting) can play an important role in this decision. Homeowners living in declining communities often face substantial barriers to relocating, including difficulty selling their home and reduced purchasing 
power if home prices have fallen. They may therefore be more likely to try to improve or maintain their neighborhoods through political and civic participation, not only as a wealth-building activity but as a lower cost alternative to moving (Cox, 1982). Renters, however, incur fewer expenses when they move; therefore, the benefits associated with moving out of an undesirable area may outweigh the costs. For homeowners, especially those with lower incomes and fewer resources, the costs associated with moving are often greater than the potential benefits.

Third, homeowners may be more politically active at the local level than renters are because they have a greater attachment to their communities simply by virtue of being homeowners. Although selection issues affect earlier research in this area, findings suggest that, among lower income families living in comparable areas, homeowners have increased informal interaction with their neighbors the longer they live in their homes (Rohe and Stegman, 1994; Rohe and Basolo, 1997). Homeowners also tend to be more satisfied with their communities in general (Rossi, 1996). Putting aside the economic incentive for political participation, we argue that homeowners will be more politically involved in their communities because they feel more "a part of" their neighborhoods by virtue of owning a part of the community.

The link between homeownership and local political participation has been partially substantiated through previous empirical research. Many studies have found that homeowners are more likely than renters to participate in voluntary associations, local political groups, and nonprofessional organizations (Cox, 1982; DiPasquale and Glaeser, 1999; Guest and Oropesa, 1986; Rossi, 1996). Herbert and Belsky (2006) recently reviewed the research on voting behaviors and found that most studies conclude that homeowners are more likely to vote than are renters (DiPasquale and Glaeser, 1999; Squire, Wolfinger, and Glass, 1987). Rossi and Weber (1996: 23) analyzed a variety of nationally representative data sets and found that owners were "almost consistently more engaged in local politics" than renters and were more likely to vote in national elections. Although suggestive, these studies cannot be taken as conclusive evidence because they have generally failed to address selection bias. Rohe, Van Zandt, and McCarthy (2000) suggested that the relationship between ownership and political participation may be spurious and the possibility that people who are politically active are more likely to become homeowners cannot be ruled out. They wrote, "Although unlikely, there may be a more fundamental orientation toward social involvement that predisposes people both to participate in voluntary and political activity and to purchase homes" (Rohe, Van Zandt, and McCarthy, 2000: 397).

Even if the relationship between homeownership and voting remains after adjusting for selection, research needs to expand beyond general outcomes to consider context-specific effects. Previous research has largely overlooked the possibility that the relationship between homeownership and local voting may be moderated by other factors. Gilderbloom and Markham (1995) compared the political participation of owners and renters by income. They found that wealthier owners are more politically active than wealthier renters are, but they found no difference between owners and renters with incomes below the median income for their communities.

This article proposes that a key component omitted from these analyses is neighborhood context. In addition to addressing selection concerns while testing individual-level predictors related to the homeownership-political participation relationship, the article examines neighborhood conditions that may fundamentally alter this relationship. Neighborhood context is an important variable to 
include both as a potential moderating variable and as an independent variable affecting voting, because neighborhood conditions are likely to influence political participation, particularly at the local level.

\section{Neighborhood Conditions}

Researchers have traditionally suggested that people who live in neighborhoods with higher crime rates or more public disorder experience lower levels of collective efficacy, civic engagement, and neighborhood satisfaction (Sampson and Raudenbush, 1999). If residents lack access to social and cultural resources, they may view political participation as futile and resign themselves to living in an undesirable area (Brady, Verba, and Schlozman, 1995). Rohe, Van Zandt, and McCarthy (2000) cautioned that neighborhood revitalization efforts that focus on increasing homeownership in disadvantaged neighborhoods could result in homeowners feeling trapped in depreciating neighborhoods that offer them few opportunities for civic or community involvement. It is therefore possible that homeowners in less desirable neighborhoods may experience greater dissatisfaction than comparable renters do because they lack mobility. Furthermore, even homeowners who do feel they have the option to move may be reluctant to do so because they feel a stronger sense of attachment and commitment to their local communities than renters do.

On the other hand, homeowners in disadvantaged areas could actually become more politically active to protect their investment in their neighborhood. Although they may be skeptical about whether local voting yields tangible neighborhood improvements, many lower income homeowners simply may not have the option to move without taking a damaging financial loss on their homes. In addition to assuming the economic costs associated with moving — costs that many lower income families may not be able to afford-low-income homeowners assume social costs as well. Low-income families are more dependent on social ties than wealthier families are, and they derive greater well-being from their community-based support networks (Gladow and Ray, 1986). Therefore, even if neighborhood conditions decline, relocating may not be a viable or desirable option for low-income homeowners. As evidence of this observation, studies have found that lower income families are less likely than middle-class families to translate neighborhood dissatisfaction into a move (South and Deane, 1993). Combined, these findings suggest that neighborhood context should be an important consideration when examining any association between homeownership and local political participation, but any model of that relationship needs to also account for endogeneity and selection effects.

\section{Conceptual Model}

Based on the framework outlined previously, the conceptual model proposed in this article is designed to explore the relationship between homeownership and voting in local elections and to consider whether neighborhood conditions moderate that relationship. This model is depicted in exhibit 1.

The model first tests the relationship predicting homeownership, link A in exhibit 1. Although this link has been established in past studies, it provides the base model for subsequent analyses. The second-stage model tests the relationship between homeownership and local voting, link B. This 


\section{Exhibit 1}

\section{Theoretical Model}

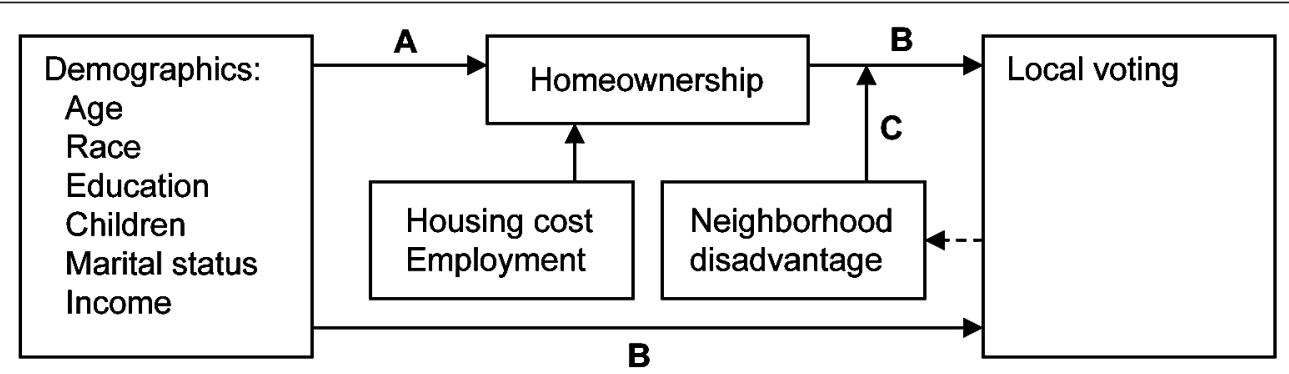

model incorporates both homeownership and the direct effects of the demographic variables. The study first models only the direct effect of homeownership, net the influence of the variables from the first-stage model. An added interaction term then evaluates the moderating effect of neighborhood disadvantage on the homeownership-political participation relationship, link C.

As shown in the conceptual model, this study recognizes the likelihood of a reciprocal relationship between voting and neighborhood disadvantage (shown in the dashed line). Neighborhoods where people are politically active and engaged are likely to improve. Although the model acknowledges this relationship, this study does not test it empirically because it uses cross-sectional data.

\section{Data}

The study tested the theoretical model described previously using data collected for the Community Advantage Program (CAP) study. CAP is a secondary mortgage market program developed out of a partnership between the Ford Foundation, Fannie Mae, and Self-Help, a leading community development financial institution located in Durham, North Carolina. To qualify for the program, participants had to meet one of the following criteria: (1) have an annual income of no more than 80 percent of the Area Median Income (AMI), (2) be a minority with an income not in excess of 115 percent of AMI, or (3) purchase a home in a high-minority ( $>30$ percent minority residents) or low-income ( $<80$ percent of AMI) census tract and have an income not in excess of 115 percent of AMI. By the end of 2004, 38,573 families had purchased homes through CAP.

This study's data originated from a survey designed to evaluate the effects of homeownership on families who purchased homes through CAP. To facilitate this analysis, a random sample of CAP borrowers participated in a survey covering social and financial outcomes related to homeownership. After we selected the sample of homeowners, we matched a comparison group of renters to the homeowners based on neighborhood proximity and income. This matching was limited to the 30 metropolitan areas in the United States with the highest numbers of CAP owners. The renter sample was obtained by randomly selecting households that lived within the same census blocks ${ }^{1}$ as homeowners already enrolled in CAP, based on public telephone directory lists. Similar

\footnotetext{
${ }^{1}$ When eligible renters could not be found within the census block, we expanded the radius up to 4 miles.
} 
to the CAP homeowners, the renters had to meet income or racial criteria. Respondents had to be between 18 and 65 years old, pay rent to the owner of their residence, and have an annual income of less than 80 percent of AMI or 115 percent of AMI in a predominantly minority neighborhood. (Center for Community Capital, 2005). The final matched sample of participants was composed of 1,671 homeowners and 1,530 renters for a total of 3,201 participants.

Because the CAP homeowners sample is not a random sample, the study managers compared CAP with the sample of low-income homeowners who participated in the 2004 Current Population Survey (CPS) in order to assess how CAP compares with a random national sample (Riley and $\mathrm{Ru}, 2009)$. The sociodemographic composition of CAP is very similar to the CPS sample. CAP includes a greater percentage of men because the primary respondent was designated based on the first name to appear on the mortgage deed. The CAP sample also includes a greater percentage of minority respondents because one of the goals of the original program was to increase minority homeownership. The only other notable difference between CAP and CPS is that more than 90 percent of CAP homeowners are employed, compared with only 70 percent of CPS low-income homeowners. The authors presume this difference is because all CAP owners purchased their homes fairly recently and therefore had to have a steady source of income at that time, while the CPS owners likely include more retirees who purchased their homes much earlier.

In this study, the authors reduced the analytic sample to exclude nonurban participants who lived outside a metropolitan statistical area (MSA), because neighborhood effects are less meaningful in rural communities. The study also excluded participants who were not registered to vote, because they would be ineligible to manifest the outcome of interest (voting). Therefore, the findings apply only to registered voters in urban neighborhoods. The final analytic sample includes 1,836 respondents, 60 percent of whom were homeowners. Because the study excluded respondents who were not registered to vote in 2004, the sample of participants includes very few Hispanic respondents (8 percent), who are more likely than Whites or African Americans to be undocumented residents.

\section{Methods}

Dietz and Haurin (2003) pointed out that endogeneity issues are especially problematic in this line of research because it is plausible that people who are predisposed toward civic engagement may be more likely to want to buy homes and establish themselves within a community. Many variables that are known to influence or predict homeownership are also associated with social outcomes such as voting (Gilderbloom and Markham, 1995; Haurin, Parcel, and Haurin, 2002; Rossi, 1996). The best way to examine such a possibility would be through longitudinal studies that can compare civic participation attitudes and activities before and after homeownership. Such studies are rare, however, and are often limited in terms of generalizability. ${ }^{2}$

The authors address the issue of endogeneity by using a bivariate probit model, which is suitable when an overlapping set of covariates appears in each of two equations (Greene, 1999; McLanahan and Sandefur, 1994). In this case, a common set of variables predicts both homeownership and

\footnotetext{
${ }^{2}$ One such study of low-income Baltimore homeowners by Rohe and Stegman (1994), for example, found that homeowners' level of participation in neighborhood associations increased after they became owners compared with the level of participation of continuing renters; however, Rohe and Stegman did not find increases in other forms of civic engagement.
} 
political participation. Greene (1999) shows that a seemingly unrelated bivariate probit model is appropriate when the dependent variable from the first equation appears as an independent variable in the second equation. The authors therefore use the predicted probability of homeownership (dependent variable) from the first model as an independent variable in the second equation that predicts voting and estimate this model using the /biprobit/ routine in Stata ${ }^{\circledR}$.

\section{Measures}

Descriptive statistics for all variables are presented in exhibit 2 . The dependent variable for the first-stage model is an indicator for homeownership. Owners are coded 1 and renters are coded 0. This measure is then instrumented and becomes the key independent variable in the second equation predicting voting.

The dependent variable of interest is local voting. First, we asked respondents, "Are you registered to vote where you live now?" We then excluded respondents who were not registered to vote. We then asked respondents who said they were registered to vote, "Did you vote in the last local election?" We coded responses as an indicator variable with yes answers coded as 1 and others as 0 .

It is important to note that some overreporting of voting for social desirability reasons is likely. Estimates based on National Election Survey data indicate that between 25 and 30 percent of respondents incorrectly report whether they voted in the previous election. Most of these respondents are people who report having voted when they did not (Tanur, 1992). Although overreporting happens across the sociodemographic spectrum, a few trends are worth noting. First, several previous studies have found that residents of southern states have higher rates of overreporting than residents of other states (Jones, 2008). Because the owners and renters in this study are matched by neighborhood, the geographic distribution of overreporting does not bias the results regarding homeownership and voting. The only other pattern in overreporting that has been substantiated by multiple studies is that African Americans have higher rates of overreporting than Whites do. This finding, however, has been based on examining the population as a whole. When Silver, Anderson, and Abramson (1986) examined only overreporting among eligible registered voters who claimed that they had voted, the race factor was not statistically significant. We do recognize that overreporting of voting likely contributes to the frequency of voting reported among the CAP respondents, and we acknowledge this issue as a limitation of the present study. Such overreporting, however, is not thought to significantly bias the findings of this research.

Neighborhood disadvantage is measured using an index measure based on research by Sampson et al. (2002) to develop a reliable measure of "concentrated disadvantage" at the tract level. Sampson and colleagues used measures of the percentage of single parents, non-White residents, unemployed persons, families on public assistance, and households below the poverty line. These measures are specifically selected to represent the latent concept of localized community wealth and economic advantage, particularly the geographic isolation and multiple layers of disadvantage experienced in some poor, predominantly minority, urban areas. Each element of the index is transformed to a z-score, and the z-scores are summed together and divided by 5 (Benson et al., 2003). Previous research has found that neighborhoods with higher concentrated disadvantage also have higher rates of adolescent delinquency, infant and adult health problems, violent crime, and high school attrition (Brooks-Gunn, Duncan, and Aber, 1997). 


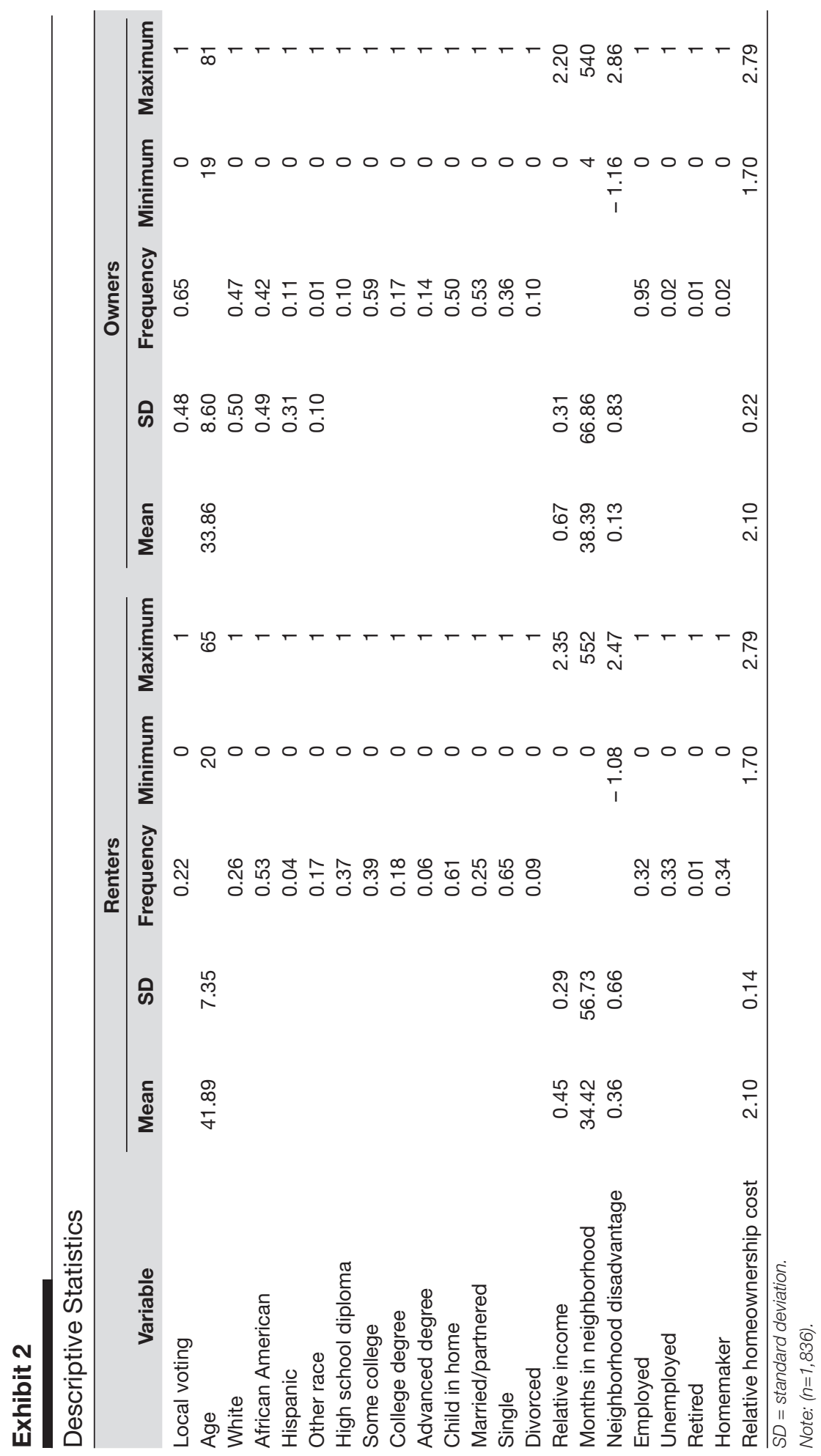




\section{Instrumental Variables}

The first-stage model predicting homeownership contains two instrumental variables, variables that predict homeownership but not voting. Following Green and White (1997), the first variable is MSA relative homeownership cost. This variable is a ratio of the median monthly housing cost for owners holding a mortgage to the median rent paid by renters. The variable is calculated at the MSA level using census data. The relative homeownership cost is an ideal measure for instrumenting homeownership, because it is strongly correlated with homeownership rate (Green and White, 1997). The second instrumental variable is employment status. Employment status is measured using a series of indicator variables for employed, unemployed, retired, and not in the paid labor force (homemaker). The reference category is employed. Employment status is significantly correlated with homeownership but is not correlated with local voting in the CAP data set. ${ }^{3}$

\section{Control Variables}

Most of the control variables in the bivariate probit model significantly predict both homeownership and voting and thus appear in both equations. The control variables include age, race/ ethnicity, education, family composition, marital status, relative income, and length of time in the neighborhood. Age is measured as a continuous variable and is top-coded at 80. Race/ethnicity is measured using indicator variables for African American, White, Hispanic, and other race. The reference category is White. Education is also measured using indicator variables. The categories are high school diploma or less, some college, college graduate, and advanced degree. The reference group in all models is high school diploma or less. Family composition is measured by an indicator variable for whether a family has children living at home. Those with children are coded 1 and those without children are coded 0. Marital status is measured using indicator variables for married/ partnered, single, and divorced. The reference is married/partnered. Relative income is measured as the ratio of total household income to mean household income at the MSA level. This measurement accounts for geographic differences in the cost of living. Finally, we measure the length of time a respondent has lived in the neighborhood in months using a continuous variable.

\section{Findings}

Exhibit 3 presents the results from the first equation in the bivariate probit model. This equation predicts homeownership and does not change across all the models. We therefore present it only once, in exhibit 3 , but readers should note that this equation generates the instrumented homeownership variable that is used in all the remaining analyses. The parameter estimates in the bivariate probit model are not directly interpretable, so we limit our discussion to the direction of significant effects (Gensler and Walls, 1997; Stolzenberg, 2001).

Unlike Green and White (1997), we find that the likelihood of homeownership increases as the relative cost of owning a home versus renting increases. One possible reason for this increase is that people may be more inclined to purchase homes when house values overall are appreciating rapidly, because they see housing as a good investment with the potential for strong returns.

\footnotetext{
${ }^{3}$ Models supporting the selection of MSA median housing cost and employment status as instrumental variables are available from the authors on request.
} 


\section{Exhibit 3}

\begin{tabular}{|c|c|c|}
\hline \multicolumn{3}{|c|}{ Coefficients From Bivariate Probit Model Instrumenting Homeownership } \\
\hline Variable & Coefficient & Standard Error \\
\hline MSA relative homeownership cost & $1.74^{\star \star *}$ & 0.27 \\
\hline Unemployed $^{\mathrm{a}}$ & $-1.85^{\star \star \star}$ & 0.17 \\
\hline Retired $^{a}$ & 0.46 & 0.32 \\
\hline Homemakera & $-1.81^{\star \star \star}$ & 0.17 \\
\hline Age & $-0.04^{\star \star \star}$ & 0.01 \\
\hline African American ${ }^{\mathrm{b}}$ & 0.56 *** & 0.12 \\
\hline Hispanic ${ }^{b}$ & $-0.41^{*}$ & 0.18 \\
\hline Other race ${ }^{b}$ & $-1.06^{\star \star *}$ & 0.24 \\
\hline Some college ${ }^{c}$ & $0.75^{\star \star *}$ & 0.12 \\
\hline College degree & $0.54^{* * *}$ & 0.17 \\
\hline Advanced degree $^{c}$ & $1.07^{* \star *}$ & 0.20 \\
\hline Child(ren) in home & -0.17 & 0.11 \\
\hline Single ${ }^{d}$ & $-1.23^{\text {***}}$ & 0.13 \\
\hline Divorced $^{d}$ & $-0.39^{*}$ & 0.13 \\
\hline Relative income & $1.25^{\star \star \star}$ & 0.16 \\
\hline Constant & $-2.05^{\star \star *}$ & 0.64 \\
\hline athrho & $-0.44^{\star \star \star}$ & 0.11 \\
\hline rho & -0.41 & 0.09 \\
\hline
\end{tabular}

MSA = metropolitan statistical area.

${ }^{a}$ Reference group is employed.

${ }^{b}$ Reference group is White.

${ }^{c}$ Reference group is high school diploma or less.

${ }^{d}$ Reference group is married.

${ }^{\star} p<0.05 .{ }^{* *} p<0.01 .{ }^{* *} p<0.001$.

Note: $(n=1,836)$.

Another explanation could be that average rents in some inner-city neighborhoods are so low that, even when owning a home costs significantly more than renting, owning is still an affordable option. Regardless of the reason, the relative homeownership cost variable is statistically significant and therefore functions as an appropriate instrumental variable. The direction of the relationship is not relevant to the model.

People who are unemployed or homemakers are less likely to be homeowners. Older respondents are slightly less likely to own a home. The model indicates that, compared with Whites, African Americans are more likely to be homeowners. This finding contradicts past studies but is likely due to our focus on urban residents in low-income and high-minority neighborhoods and is, therefore, an artifact of the CAP sample. People who have any education beyond high school are more likely to be homeowners. As expected, single and divorced people are less likely to be homeowners than are married couples. Finally, people with higher incomes are more likely to be homeowners.

Exhibit 4 presents the second half of the bivariate probit model. This equation uses the instrumented homeownership variable and the independent variable for neighborhood disadvantage to predict a respondent's likelihood of having voted in his or her community's most recent local election. Model 1 finds that homeowners are more likely than renters to have voted in the most recent local election. When looking at the control variables, we find that Hispanic and "other race" 


\section{Exhibit 4}

Local Voting Regressed on Homeownership and Neighborhood Disadvantage: Bivariate Probit Model

\begin{tabular}{|c|c|c|c|c|c|c|}
\hline \multirow[b]{2}{*}{ Variable } & \multicolumn{2}{|c|}{ Model 1} & \multicolumn{2}{|c|}{ Model 2} & \multicolumn{2}{|c|}{ Model 3} \\
\hline & Coefficient & $\begin{array}{l}\text { Standard } \\
\text { Error }\end{array}$ & Coefficient & $\begin{array}{l}\text { Standard } \\
\text { Error }\end{array}$ & Coefficient & $\begin{array}{l}\text { Standard } \\
\text { Error }\end{array}$ \\
\hline $\begin{array}{l}\text { Homeowner } \\
\text { (instrumented) }\end{array}$ & $1.38^{\star \star \star}$ & 0.17 & $1.44^{\star \star *}$ & 0.17 & $1.37^{\star \star \star}$ & 0.17 \\
\hline $\begin{array}{l}\text { Neighborhood } \\
\text { disadvantage }\end{array}$ & & & $0.17^{\star \star}$ & 0.06 & 0.01 & 0.10 \\
\hline $\begin{array}{l}\text { Homeownership*nei. } \\
\text { disadvantage }\end{array}$ & & & & & 0.22 * & 0.11 \\
\hline African American ${ }^{a}$ & 0.09 & 0.10 & -0.01 & 0.10 & -0.02 & 0.11 \\
\hline Hispanic $^{a}$ & $-1.66^{\star \star *}$ & 0.19 & $-1.80^{\star \star *}$ & 0.19 & $-1.84^{\star \star \star}$ & 0.20 \\
\hline Other race ${ }^{\mathrm{a}}$ & $-1.41^{\star \star *}$ & 0.27 & $-1.40^{* * *}$ & 0.27 & $-1.51^{\star \star *}$ & 0.27 \\
\hline Age & $0.03^{\star * *}$ & 0.00 & $0.03^{* * *}$ & 0.00 & $0.03^{* \star *}$ & 0.00 \\
\hline Single ${ }^{b}$ & $0.41^{\star \star *}$ & 0.12 & $0.40^{* \star *}$ & 0.12 & $0.37^{\star \star}$ & 0.12 \\
\hline Divorced $^{\mathrm{b}}$ & -0.08 & 0.13 & -0.04 & 0.13 & -0.07 & 0.13 \\
\hline Some college ${ }^{c}$ & $1.44^{\star \star *}$ & 0.12 & $1.45^{\star \star \star}$ & 0.12 & $1.45^{\star \star \star}$ & 0.12 \\
\hline College degree ${ }^{c}$ & $1.78^{\star \star \star}$ & 0.16 & $1.72^{\star \star \star}$ & 0.16 & $1.68^{\star \star \star}$ & 0.16 \\
\hline Advanced degree $^{c}$ & $1.52^{\star * *}$ & 0.17 & $1.43^{* * *}$ & 0.18 & $1.38^{* * *}$ & 0.18 \\
\hline Child(ren) in home & $-0.38^{\star \star \star}$ & 0.08 & $-0.35^{* * *}$ & 0.09 & $-0.38^{\star \star \star}$ & 0.09 \\
\hline Relative income & -0.30 * & 0.13 & $-0.31 *$ & 0.13 & $-0.31 *$ & 0.13 \\
\hline Months in neighborhood & 0.00 & 0.00 & 0.00 & 0.00 & 0.00 & 0.00 \\
\hline Constant & $-2.70^{\star * *}$ & 0.25 & $-2.63^{* \star *}$ & 0.25 & $-2.53^{\star \star \star}$ & 0.26 \\
\hline $\mathrm{N}$ & 1,836 & & 1,836 & & 1,836 & \\
\hline Wald chi2 & $1,512.78$ & & $1,507.05$ & & $1,505.63$ & \\
\hline Log likelihood & $-1,209.53$ & & $-1,205.08$ & & $-1,203.23$ & \\
\hline
\end{tabular}

a Reference group is White.

${ }^{b}$ Reference group is married.

${ }^{c}$ Reference group is high school diploma or less.

${ }^{*} p<0.05$. ${ }^{* *} p<0.01$. ${ }^{* * *} p<0.001$.

Note: $(n=1,836)$.

respondents are much less likely to have voted compared with Whites. Older respondents are slightly more likely to have voted, as expected, as are single respondents. Respondents at all other education levels are significantly more likely to vote compared with those who have only a high school diploma or less. The presence of children in the home is associated with a decline in voting likelihood. Relative income and length of time in the neighborhood have no effect on local voting.

Model 2 tests the significance of neighborhood disadvantage in the model. We find a small yet significant relationship. People who live in more disadvantaged neighborhoods are slightly more likely to have voted in their most recent local election. In addition to finding a direct effect, we also found that neighborhood disadvantage moderates the relationship between homeownership and local voting, as shown in model 3. The interaction term for neighborhood disadvantage and homeownership is significant, indicating that homeowners in disadvantaged neighborhoods are even more likely to vote than either owners in less disadvantaged areas or renters in comparable neighborhoods. 


\section{Predicted Probability of Voting}

As discussed previously, it is difficult to interpret the coefficients in a bivariate probit model. To evaluate how great an effect homeownership and neighborhood disadvantage have on voting, we calculated the predicted probabilities of local voting for homeowners and renters varying by neighborhood disadvantage score, holding all other variables constant at the mean.

Exhibit 5 presents a graph of the predicted probability of a respondent having voted in the most recent local election based on model 3 in exhibit 4 . A significant gap exists between owners and renters, with homeowners predicted to vote at much higher levels than renters. Recall that these lines show the predicted probability of voting, not whether any given respondent actually voted. Exhibit 5 shows that, as neighborhood disadvantage increases, homeowners are more likely to vote in local elections. From the least to the most disadvantaged neighborhood, homeowners' predicted probability of voting increases by approximately 30 percent. Voting by renters, however, remains nearly constant and significantly lower than voting by owners. In summary, as neighborhood disadvantage increases, homeowners are more likely to become politically active at the local level, where their actions have the most potential to improve their neighborhoods and local communities.

\section{Exhibit 5}

\section{Local Voting Predicted Probability by Neighborhood Disadvantage and Tenure Status}

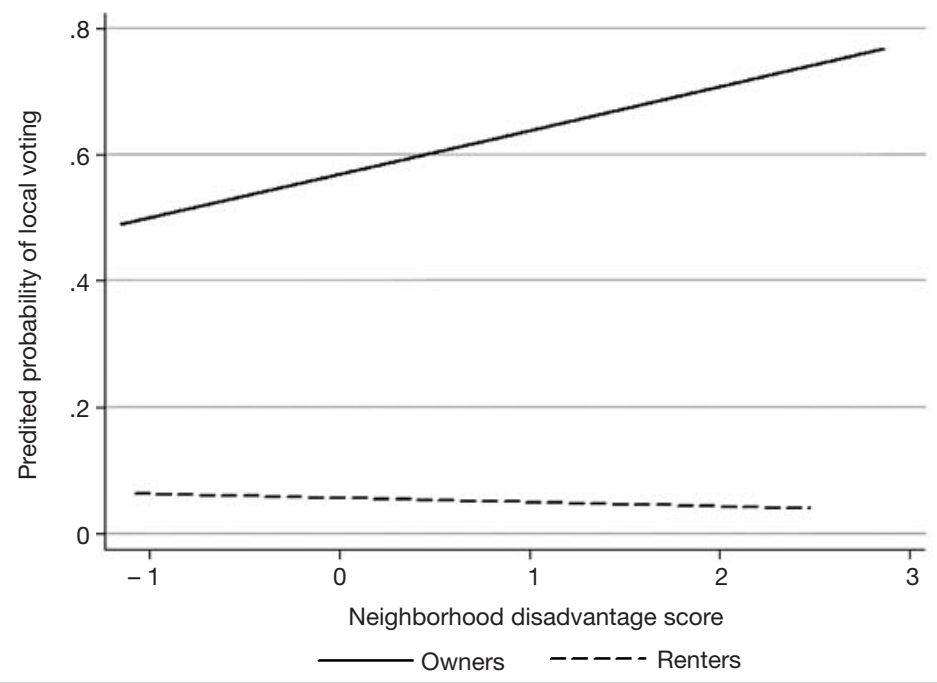

\section{Discussion}

The objective of this study was threefold: (1) address selection bias concerns in the research on the relationship between homeownership and local voting, (2) test the relationship between homeownership and voting, and (3) test whether neighborhood disadvantage moderates that relationship. We used a seemingly unrelated bivariate probit model to model homeownership and political participation as a two-stage model. We first predicted homeownership using two 
instrumental variables, MSA median housing cost and employment status, which are correlated with homeownership but not with local voting. The model also includes a set of sociodemographic variables likely predictive of both homeownership and political participation: age, race, relative income, education, marital status, and family composition. The model then uses predicted probabilities of homeownership from the first-stage model as the independent variable for homeownership in the second-stage model. By using this technique, we were able to measure the direct effect of homeownership on local voting, independent of the common sociodemographic predictors that both outcomes share. This technique is a substantial improvement over previous studies that have failed to account for the fact that homeownership itself is an endogenous variable within any model predicting social outcomes.

Our findings further clarify the selection issue. Recall that selection bias poses a problem, because people who self-select to become homeowners may do so for unobserved reasons, such as being very civic minded, which may also predict voting. We found that homeowners in the most disadvantaged neighborhoods are the most likely to vote. It is highly unlikely that the most civicminded people would intentionally select to move into the most disadvantaged communities, so we have little reason to suspect that these results are biased.

Regarding the relationship between homeownership and voting, we found that homeownership does have an independent effect on local political participation. Owners are more likely than renters to have voted in their most recent local elections. This finding confirms results from previous studies on political participation and homeownership and indicates that, contrary to Rohe, Van Zandt, and McCarthy's (2000) suggestion, the relationship is not spurious.

We found that neighborhood disadvantage also has an independent effect on political participation. People in disadvantaged neighborhoods are more likely to have voted in their most recent local election. Lastly, we found that there is an interaction effect between homeownership and neighborhood disadvantage regarding political participation. Homeowners who live in disadvantaged neighborhoods are more likely to vote in local elections than both homeowners in less disadvantaged areas and renters. As neighborhood distress increases, homeowners show significant increases in voting, while renters' voting behavior remains constant.

Taken together, these findings support the claim that homeownership can potentially spur political participation regardless of neighborhood conditions. In fact, homeownership is most beneficial as a catalyst for political participation and potential community improvement in neighborhoods that are facing higher levels of concentrated disadvantage. We found that homeownership can provide a pathway to positive social change in two ways. First, homeownership leads to increased local political participation, even for lower income owners living in disadvantaged neighborhoods. Political engagement is a crucial element of democracy and one of the most accessible avenues through which ordinary citizens can participate in civic life. By increasing political involvement within disadvantaged neighborhoods, homeownership contributes to the empowerment of those urban communities. Homeownership also benefits communities as a whole, because involved, engaged citizens are more likely to create positive neighborhood-level changes. As residents become more involved in local politics, they are more likely to actualize the positive changes they seek for their communities. 
At the same time, individual-level costs associated with homeownership in disadvantaged neighborhoods need to be acknowledged. Although homeownership brings collective benefit to these areas, individual owners who live there likely invest a disproportionate amount of time in creating improvements, relative to owners in more desirable areas. Any policies intended to promote homeownership in disadvantaged areas must consider whether potential homeowners would have access to housing in a more desirable neighborhood if they elected to defer homeownership.

It is also important to note, especially in light of the recent housing downturn in the United States, that all homeowners who participated in CAP received prime, fixed-rate, 30-year mortgages with a 38-percent debt-to-income limit. Research suggests that risky mortgage products-subprime (high-interest) mortgages and adjustable-rate mortgages — are bad for both homeowners and neighborhoods. Not only do risky mortgage products increase a borrower's risk of default, but even people with prime-rate mortgages who live in neighborhoods with a high rate of subprime lending have a significantly higher default risk (Ding et al., 2008). We therefore stipulate that our conclusions on the individual and community benefits of homeownership are predicated on homebuyers obtaining responsible mortgage products that do not create financial strain.

These findings suggest several directions for future research in this area. Although we have demonstrated a link between voting in local elections and homeownership, other forms of community involvement have not been explored. Are homeowners in disadvantaged communities more likely to participate in neighborhood groups or volunteer in community events? Future research can test whether homeownership also promotes forms of neighborhood involvement that require more time and effort than voting does. We also plan to build on these findings by testing whether the relationship between homeownership and voting changes over time. One strength of the CAP data set is that it provides longitudinal measures of most outcomes. We can therefore examine whether homeowners continue to vote in greater numbers over time, or whether there is a dropoff in voting after people have been homeowners for several years.

Based on our findings, our conclusion is that policies promoting and facilitating homeownership in disadvantaged neighborhoods should be encouraged, because homeownership in such neighborhoods leads to greater local political participation and community involvement. Whether homeowners stay in disadvantaged areas out of necessity or by choice, they demonstrate a commitment to improving their neighborhoods through local political involvement. Rather than resigning themselves to being "trapped" in an undesirable area, lower income homeowners capitalize on the community participation opportunities that are available. This participation benefits individual homeowners by protecting their wealth and long-term equity and also benefits struggling neighborhoods by promoting active citizenship and fostering a sense of collective efficacy and civic engagement.

\section{Acknowledgments}

The authors thank the following people for their assistance and feedback on this research: Bert Grider, Jessica Pearlman, Janneke Ratcliff, Allison Freeman, Jong-Gyu Paik, Andrew Perrin, and Jon Spader. This project was supported by a grant from the Ford Foundation to the Center for Community Capital at The University of North Carolina at Chapel Hill. 


\section{Authors}

Kim Manturuk is a research associate at the Center for Community Capital, The University of North Carolina at Chapel Hill.

Mark Lindblad is the research director at the Center for Community Capital, The University of North Carolina at Chapel Hill.

Roberto G. Quercia is the director of the Center for Community Capital and a professor in the Department of City and Regional Planning, The University of North Carolina at Chapel Hill.

\section{References}

Aaronson, Daniel. 2000. "A Note on the Benefits of Homeownership," Journal of Urban Economics 47: 356-69.

Benson, Michael L., Greer L. Fox, Alfred DeMaris, and Judy Van Wyk. 2003. "Neighborhood Disadvantage, Individual Economic Distress and Violence Against Women in Intimate Relationships," Journal of Quantitative Criminology 19: 207.

Brady, Henry E., Sidney Verba, and Kay L. Schlozman. 1995. "Beyond SES: A Resource Model of Political Participation," The American Political Science Review 89: 271-94.

Brooks-Gunn, Jeanne, Greg J. Duncan, and J. Lawrence Aber, eds. 1997. Neighborhood Poverty, Vol. I: Context and Consequences for Children. New York: Russell Sage Foundation.

Center for Community Capital. 2005. Creating a Low-Income Renter Panel as Part of the Evaluation of the Fannie Mae Self-Help Community Advantage Secondary Mortgage Demonstration Program.

Technical report. University of North Carolina, Center for Community Capital. http://www.ccc. unc.edu/research.php (accessed April 20, 2009).

Cox, Kevin. 1982. "Housing Tenure and Neighborhood Activism," Urban Affairs Review 18: 107-21.

Dietz, Robert, and Donald R. Haurin. 2003. "The Social and Private Micro-Level Consequences of Homeownership," Journal of Urban Economics 54: 401-49.

Ding, Lei, Roberto G. Quercia, Wei Li, and Janneke Ratcliffe. 2008. "Risky Borrowers or Risky Mortgages: Disaggregating Effects Using Propensity Score Models." Paper presented at the U.S. Department of Housing and Urban Development Tuesday Series in Washington, DC.

DiPasquale, Denise, and Edward L. Glaeser. 1999. "Incentives and Social Capital: Are Homeowners Better Citizens?" Journal of Urban Economics 45: 354-84.

Gensler, Howard J., and W. David Walls. 1997. "Labor Force and Welfare Program Participation: The Effects of Welfare," American Journal of Economics and Sociology 56: 229-41.

Gilderbloom, John I., and John P. Markham. 1995. "The Impact of Homeownership on Political Beliefs," Social Forces 73: 1589-1607. 
Gladow, Nancy W., and Margaret P. Ray. 1986. "The Impact of Informal Support Systems on the Well Being of Low Income Single Parents,” Family Relations 35: 113-123.

Green, Richard K., and Michelle J. White. 1997. "Measuring the Benefits of Homeowning: Effects on Children," Journal of Urban Economics 41: 441-461.

Greene, William H. 1999. Econometric Analysis (4th Edition). Upper Saddle River, NJ: Prentice Hall. Guest, Avery, and R.A. Oropesa. 1986. "Informal Social Ties and Political Activity in the Metropolis," Urban Affairs Review 21: 550-574.

Haurin, Donald R., Toby L. Parcel, and R. Jean Haurin. 2002. "Does Homeownership Affect Child Outcomes?" Real Estate Economics 30: 635-66.

Herbert, Christopher, and Eric Belsky. 2006. The Homeownership Experience of Low-Income and Minority Families: A Review and Synthesis of the Literature. Research report. Washington, DC: U.S. Department of Housing and Urban Development.

Hirschman, Albert O. 1970. Exit, Voice, and Loyalty: Responses to Decline in Firms, Organizations, and States. Cambridge, MA: Harvard University Press.

Jones, Emily. 2008. "Vote Overreporting," Policy Perspectives 15: 83-98.

Lawless, Jennifer L., and Richard L. Fox. 2001. "Political Participation of the Urban Poor," Social Problems 48: 362-85.

McLanahan, Sarah, and Gary Sandefur. 1994. Growing Up With a Single Parent: What Hurts, What Helps. Cambridge, MA: Harvard University Press.

Orbell, John M., and Toru Uno. 1972. "A Theory of Neighborhood Problem Solving: Political Action vs. Residential Mobility," The American Political Science Review 66: 471-489.

Riley, Sarah, and HongYu Ru. 2009. Community Advantage Panel Survey Technical Sampling Report: Owners 2003-2007. Report prepared for UNC Center for Community Capital. Available at http:// www.ccc.unc.edu/research.php.

Rohe, William, and Michael Stegman. 1994. "The Effects of Homeownership on the Self-Esteem, Perceived Control and Life Satisfaction of Low-Income People," Journal of the American Planning Association 60: 173-184.

Rohe, William, and Leslie Stewart. 1996. "Homeownership and Neighborhood Stability," Housing Policy Debate 7: 37-45.

Rohe, William, Shannon Van Zandt, and George McCarthy. 2000. The Social Benefits and Costs of Homeownership: A Critical Assessment of the Research. Working paper 00-01. Washington, DC: Research Institute for Housing America: 1-30.

Rohe, William M., and Victoria Basolo. 1997. "Long-Term Effects of Homeownership on the SelfPerceptions and Social Interaction of Low-Income," Environment \& Behavior 29: 793. 
Rossi, Peter, and Eleanor Weber. 1996. "The Social Benefits of Homeownership: Empirical Evidence from National Surveys," Housing Policy Debate 7: 1-34.

Sampson, Robert J., Jeffrey D. Morenoff, and Thomas Gannon-Rowley. 2002. "Assessing 'Neighborhood Effects': Social Processes and New Directions in Research," Annual Review of Sociology 28: 443-78.

Sampson, Robert J., and Stephen W. Raudenbush. 1999. "Systematic Social Observation of Public Spaces: A New Look at Disorder in Urban Neighborhoods," The American Journal of Sociology 105: 603-651.

Shlay, Anne B. 2006. "Low-Income Homeownership: American Dream or Delusion?" Urban Studies 43: $511-531$.

Silver, Brian, Barbara Anderson, and Paul Abramson. 1986. "Who Over-Reports Voting?" The American Political Science Review 80 (2): 613-624.

South, Scott J., and Glenn D. Deane. 1993. "Race and Residential Mobility: Individual Determinants and Structural Constraints," Social Forces 72: 147-167.

Squire, Peverill, Raymond E. Wolfinger, and David P. Glass. 1987. "Residential Mobility and Voter Turnout," The American Political Science Review 81: 45-66.

Stack, Carol B. 1997. All Our Kin: Strategies for Survival in a Black Community. New York: Basic Books.

Stolzenberg, Ross M. 2001. "It's About Time and Gender: Spousal Employment and Health," The American Journal of Sociology 107: 61-100.

Tanur, Judith M. 1992. Questions About Questions: Inquiries into the Cognitive Bases of Surveys. New York: Russell Sage Foundation Publications.

Wilson, William J. 1990. The Truly Disadvantaged: The Inner City, the Underclass, and Public Policy. Chicago: University of Chicago Press. 